\title{
Preliminary view on new roentgenologic trochleocapitellar index for assessment accuracy of the reduction supracondylar fracture of the elbow in children to comparison Baumann's angle
}

Lauren Gorelick ${ }^{1 *}$, Roman Gelman ${ }^{2,3}$, Ayala Rozano-Gorelick ${ }^{3}$, Anwar Saab ${ }^{3}$ and Edward Ram ${ }^{4}$

*Correspondence: gorelick@netvision.net.il

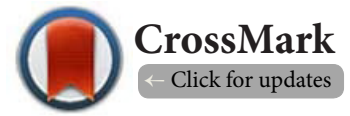

'Orthopaedic and Hand Surgeon, Assuta Medical Center, Haifa, Israel.

${ }^{2}$ Department of Orthopedics, Hillel Yaffe Medical Center, Hadera, Israel.

${ }^{3}$ Clalit Health Services-Bar Ilan medicine faculty, Zefat.

${ }^{4}$ Division of General Surgery, Rabin Medical Center-Campus Golda, Sackler School of Medicine, Tel Aviv University, Israel.

\begin{abstract}
Background: In children supracondylar fracture of the humorous is one of the most common fractures in the first decade of life. This study was conducted to establish the efficacy and the accuracy of a new own method for measuring the Trochleocapitellar index (TCI) in the management of supracondylar humeral fracture in children versus Baumann's angle.
\end{abstract}

Methods: This study made on base AP elbow radiograms and clinical charts of 54 children that were treated due to supracondylar fracture of the elbow. Cases included were of either gender with age range from four to 13 years with a supracondylar fracture presenting within 72 hours of the reduction.

Outcome measures: Two measure roentgen logic modalities studied for comparison: Baumann's angle and TCI were taken into consideration when examining the AP roentgenograms (immediately after the reduction and during 1-3 months thereafter).

$\underline{\text { Results: }}$ During 1-3 months after the reduction Baumann's angle modality gave normal results in 51 $(94.4 \%)$, valgus result in one $(1.9 \%)$ and varus result in two $(3.7 \%)$ patients. While TCI showed normal results in $31(57.4 \%)$, valgus result in one $(1.9 \%)$ and varus results in $22(40.7 \%)$ patients. Correlation was found between the measurements of the normal Baumann's angle and normal TCI immediately after fracture reduction $(\mathrm{r}=0.75, \mathrm{p}<0.001)$ and on the period between one to three months follow-up $(\mathrm{r}=0.54$, $\mathrm{p}<0.001)$. TCI was found as more accurate for detection of cubitus varus.

Conclusions: Authors recommends post reduction measurement of the TCI in supracondylar fractures to determine the adequacy of reduction.

Keywords: Children, supracondylar fracture of the humorous, cubitus varus, cubitus valgus, Baumann's angle, trochleocapitellar index

\section{Backgrounds}

Angulations deformity (cubitus varus and valgus) is the most common complication of displaced supracondylar fractures. Most deformity seems to be related to coronal plane angulations [1]. It should also be appreciated that rotation of the distal fragment often worsens varus and valgus angulations [2]. The deformity results from two factors: primary mal-reduction of the fracture and the limited remodelling in the coronal plane [3]. Prevention of angulations depends on the accurate reduction of the fracture. The gold standard in clinical practice, today, is an assessment of reduction quality using Baumann's angle. Baumann's angle formed by the intersection of a line drawn down the humeral axis and a line drawn along the growth plate of the capitellum of the elbow [4]. This angle correlates closely with the carrying angle [5]. The mean Baumann's angle is $72^{\circ} \pm 4^{\circ}$. The new $\mathrm{TCl}$ of the elbow is the ratio between the smaller trochlear and larger capitellar angles of the measured elbow (Figure 1). The rationale is that an index based on the 


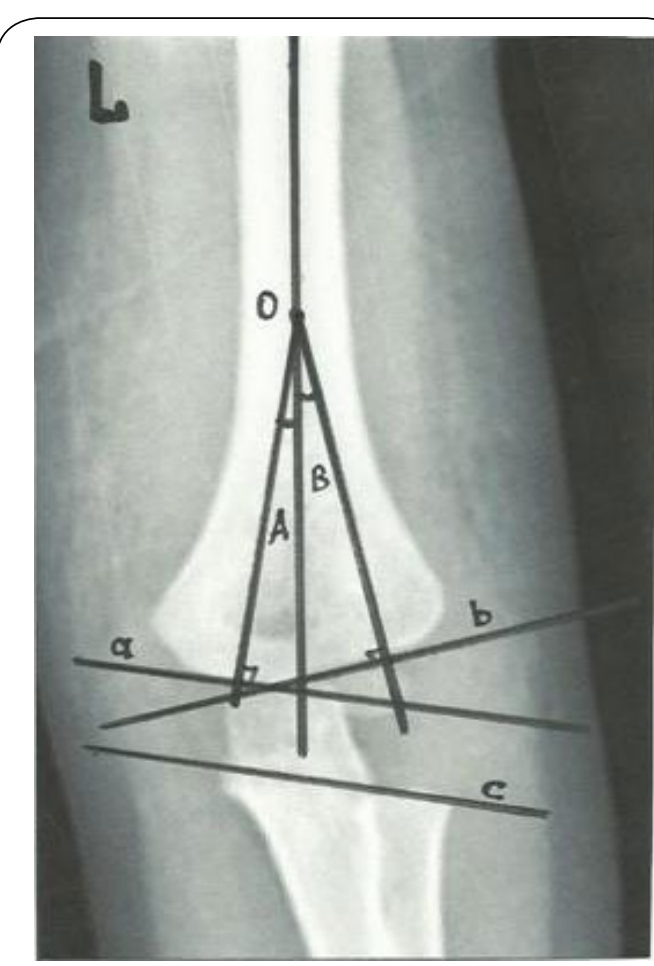

Figure 1. Schematic drawing of the anteroposterior elbow radiograph showing the components of the trochleocapitellar index.

O-humeral axis; A-trochlear angle; B-capitellar angle; a-trochlear line; b-capitellar line; $c$-alternative trochlear line drawn through the radial head growth plate and coronoid which is parallel to the trochlear line.

relationship between two angles. It is expected to be less influenced by the radiographic technique, elbow position and rotation of the distal fragment and might allow a precise evaluation of supracondylar fractures in children [6]. The object of the current study is an evaluation of the possible usefulness of a new radiographic index to comparison Baumann's angle.

\section{Materials and methods}

Roentgenograms of 54 children ( 40 boys and 14 girls) evaluated retrospectively and correlated with clinical data of a personal medical card of each one. The age range of the children in the study was from four to 13 years old (mean 7.9 years). It is the age range when most supracondylar fractures occur. The condition is rare both in infancy and after 13-years of age when the distal humeral physic undergoes fusion $[6,7]$. All evaluated children were undergoes closed or open reduction due to extension type of supracondylar fracture of the humorous Gartland type II and type III. Evaluated roentgenograms of all patients to be done immediately after reduction and one to three months after it. Baumann's angle and TCl were measurements in all roentgenograms. The $\mathrm{TCl}$ is the ratio between the two measured angles. The trochlear angle formed by intersection of a line drawn down the humeral axis and a line perpendicular to one drawn along the trochlear surface. The capitellar angle formed by intersection of a line drawn down the humeral axis and one perpendicular to a line drawn along the growth plate of the lateral condoyle (or alternative line drawn through the radial head growth plate and coronoid) (Figure 1). The means normal $\mathrm{TCl}$ was 0.45 , with a range of 0.25 to 0.8 . A TCl closer to 0.25 indicates slight valgus of the elbow. A TCl closer to 0.8 tends toward a neutral position. A $\mathrm{TCl}$ closer to 1 tends toward varus deformity [6].

\section{Statistical analysis}

Statistical analysis was performed using the SPSS statistical program. Differences in the values of the angles between the subjects inspected through Mann-Whitney U test. Differences in the values of the angles the same subjects were tested using Wilcox on signed rank test. The differences in the percentage of invention varus and valgus between the two measurement methods were tested using the chi-square test (chi-square test-X2). A difference at the 0.05 level is termed significant. Effect sizes calculated as adjusted difference in result divided by baseline standard deviation of the result.

\section{Results}

Immediately after fracture reduction, roentgenograms of all 54 children (100\%) determined as normal by measuring of Baumann's angle (median Baumann's angle $72^{\circ}\left(68^{\circ}-73^{\circ}\right)$ ). Varus or valgus deformity was not determined according to this angle. In the same roentgenograms, $\mathrm{TCl}$ was normal (median $\mathrm{TCl}-0.9(0.22-1.12)$ ) in 46 of them (85.2\%) and determined as varus in eight (14.8\%) (Figure 2). Valgus deformity was not found. In all cases that TCl determined as normal, Baumann's angle had normal range and correlated statistically with $\mathrm{TCI}$ $(r=0.75, p<0.001)$. However, in cases that $\mathrm{TCl}$ was determined as varus, Baumann's angle had being in normal range. There was a significant statistical difference between the range of values of the $\mathrm{TCl}$ between the normal and the varus results $(p<0.05)$ (Table 1). Follow-up radiographic evaluation of 54 cases one to three months after the reduction showed that Baumann's angle was normal in 51 cases (94.4\%), varus in two cases (3.7\%) and valgusin one case (1.9\%).

Measurement of the $\mathrm{TCl}$ on the same roentgenograms showed normal range in 31 cases (57.4\%), varus-in 22 (40.7\%) and valgus-in one case (1.9\%). In all cases that $\mathrm{TCl}$ was determined as normal, two as varus and one as valgus Baumann's angle had ranged accordingly and correlated statistically with TCI $(r=0.54, p<0.001)$. However, in remaining 20 cases that $\mathrm{TCl}$ determined as varus Baumann's angle had being in normal range. There was a significant statistical difference between the two evaluation methods $(p<0.05)$ (Table 2$)$.

\section{Discussion}

The elbow is a highly congruent joint with a limited remodelling capacity. The final assessment of the reduction of a supracondylar fracture in children shows the importance of 


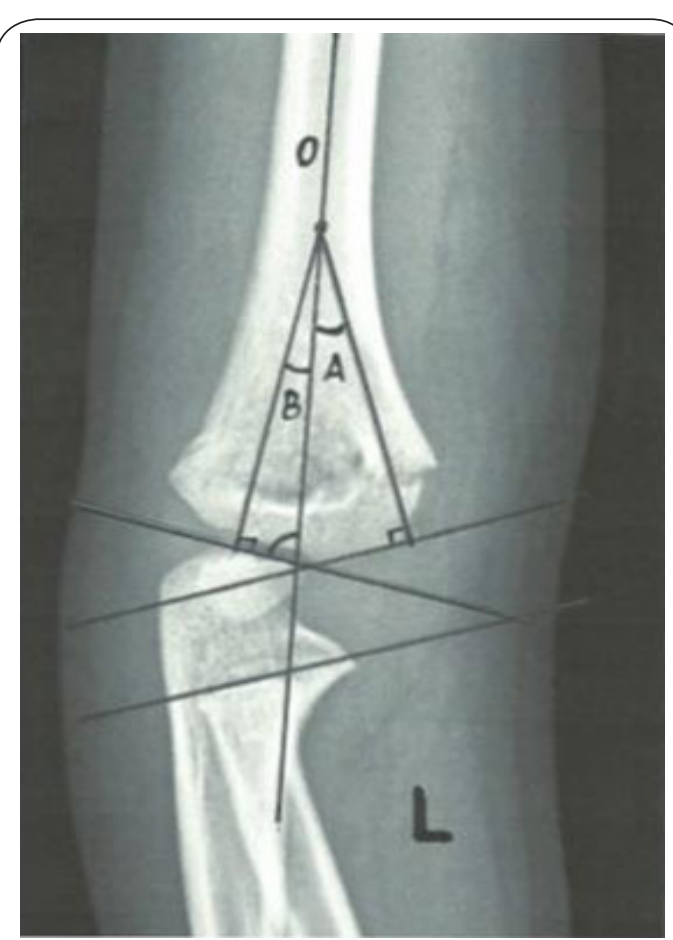

Figure 2. Radiograph immediately after fracture of the elbow. Baumann's angle is $76^{\circ}$ that accepted as normal. TCI $>1$ indicate severe varus deformity.

Table 1. Difference between measurements of a Baumann's angle and TCI of the Post-op roentgenogram.

\begin{tabular}{lllll}
\hline Post-oproentgenogram & $\begin{array}{l}\text { Normal } \\
\mathbf{n}(\%)\end{array}$ & $\begin{array}{l}\text { Varus } \\
\mathbf{n}(\%)\end{array}$ & $\begin{array}{l}\text { Valgus } \\
\mathbf{n}(\%)\end{array}$ & $\begin{array}{l}\text { Total } \\
\mathbf{n}(\%)\end{array}$ \\
\hline Baumann's angle & $54(100)$ & $0(0)$ & $0(0)$ & $54(100)$ \\
TCI & $46(85.2)$ & $8(14.8)$ & $0(0)$ & $54(100)$ \\
\hline
\end{tabular}

Table 2. Difference between measurements of a Baumann's angle and TCI of the Follow up Rx.

\begin{tabular}{lllll}
\hline Post-oproentgenogram & $\begin{array}{l}\text { Normal } \\
\mathbf{n}(\%)\end{array}$ & $\begin{array}{l}\text { Varus } \\
\mathbf{n}(\%)\end{array}$ & $\begin{array}{l}\text { Valgus } \\
\mathbf{n}(\%)\end{array}$ & $\begin{array}{l}\text { Total } \\
\mathbf{n}(\%)\end{array}$ \\
\hline Baumann's angle & $51(94.4)$ & $2(3.7)$ & $1(1.9)$ & $54(100)$ \\
TCI & $31(57.4)$ & $22(40.7)$ & $1(1.9)$ & $54(100)$ \\
\hline
\end{tabular}

preventing any angular deformity of the elbow at the time of fracture reduction. Small measurement errors might have a clinical significance. Several angels could be measured on AP radiographs in order to allow determination of the degree to which the normal alignment of the elbow has been restored $[1-3,5,6,8]$. These measurements associated with some technical difficulties that lead to difficulty in fracture alignment assessment [9]. Due to these difficulties, it is often clinically mandated to compare the injured elbow with the contralateral elbow [10]. Exposing the contra lateral elbow to radiation not only increases the radiation exposure of the children but also the cost of treatment. There is consensus that most important measurement for assessment of the fracture reduction is the Baumann's angle [1-4,10]. Unfortunately, Baumann's angle relates only to the coronal plane of a complex rotational deformity of the elbow that involves shifts from the normal anatomy in three planes. It is well known that Baumann's angle is highly dependent on the angulations of the $x$-ray beam [6]. Camp J et al., made a controlled radiographic study of a 6-year-old cadaver upper extremity specimen and remarked six degrees of change in Baumann's angle for every 10 degrees of rotation of the extremity specimen [11]. Pace $\mathrm{J} \mathrm{L}$ et al., suggest about radial-ulnar overlap as surrogate measures that could act as internal controls for the angle of the $x$-ray beam to give an accurate Baumann's angle [12]. In a review of the literature by Pretell-MazziniJ et al., Baumann's angle values were available in only few articles that expressed either as an absolute value or like a loss of angle [13]. Most authors determine the change in Baumann's angle as statistically insignificant [14-17]. Foead $A$ et al., note that only satisfactory reduction based on carrying angle and Baumann's angle assessed in an operating room were accepted. However, the Baumann's angle loss measured in 54 from 55 patients in this study at follow up [16]. Authors measured new TCI retrospectively on 54 post-op radiograms that all were determined as normal according to Baumann's angle. Eight of them (14.8\%) were determined as varus according to $\mathrm{TCl}$ with significant statistical difference. These patients had significant varus deformity in follow-up noted in personal medical cards. There is a statistical correlation between the normal values of the $\mathrm{TCl}$ and normal Baumann's angle in post-op series. These cases described as clinically normal on follow-up.

In follow-up radiographic evaluation of 54 cases, another 14 determined as varus (in addition to eight in post-op series) according to $\mathrm{TCl}$. These elbows had only slight varus toward to neutral in follow-up. Only two patients (from the same eight of post-op series) determined as varus according to the measurement of Baumann'sangle. One from 54 cases measured as valgus in both TCl and Baumann's angle without any clinical significance on the follow-up. Correlation was found between Baumann's angle and TCl whenever TCl was noted as normal, both, at post op and in follow-up period. Different degrees of varus deformity determined in 22 patients from $54(40.7 \%)$ in the present study, by the TCl (retrospective measurements of $\mathrm{TCl}$ of the same roentgenograms, eight cases $(14.8 \%)$ in post-op and 14 others (25.9\%) in followed-up roentgenograms). All of them had normal range of Baumann's angle immediately after fracture reduction, and only two had varus in follow-up roentgenograms. Cubitus varus is the most common complication of the supracondylar fracture in children and noted in different studies between four to $58 \%$ [17]. Percentage of the cubitus varus in this study by the TCI $(40.7 \%)$ is compatible with the range that is described in the literature. To the knowledge of the authors, this finding of TCI is the first of its kind. It gives the possibility to use the results 
of measurement of the $\mathrm{TCl}$ to determine better evaluation of treatment outcome of the fracture (Figure 3). The result of the present study can have implications on the general population of children with supracondylar fractures of the elbow because the sample population in this study is the same as in previous studies.

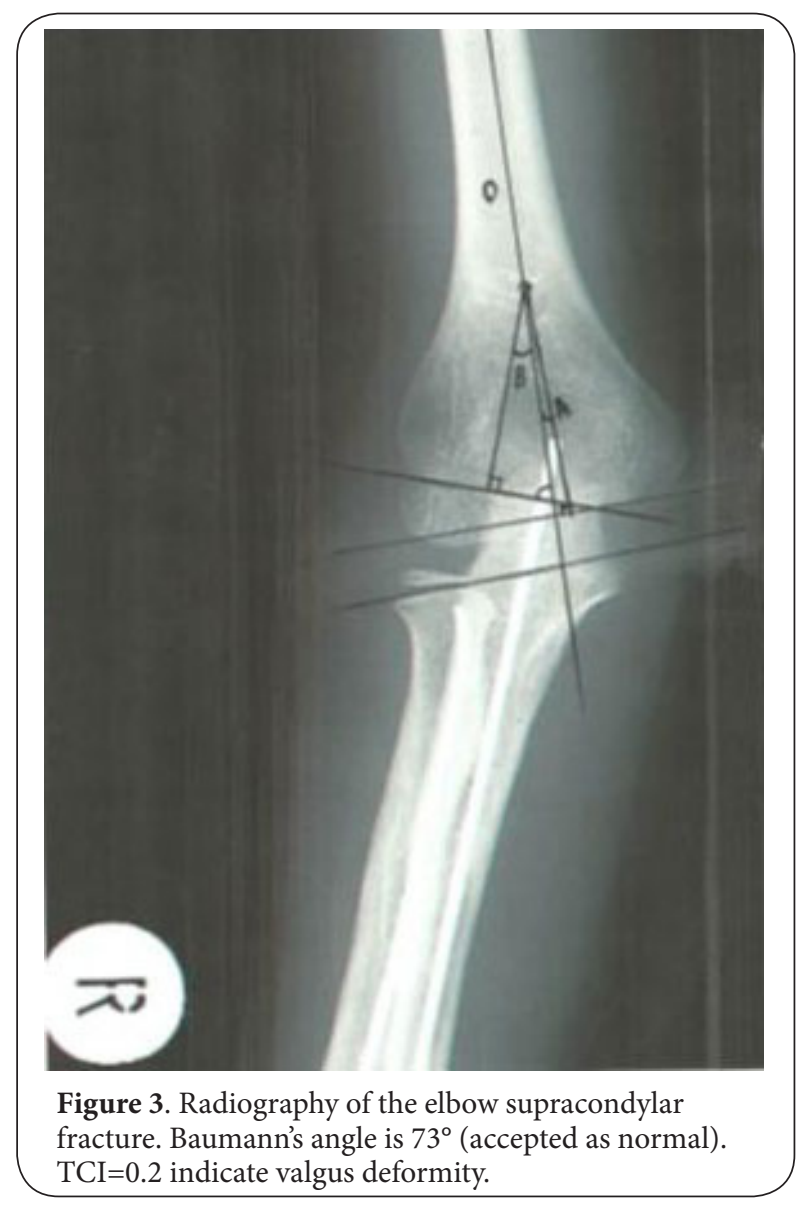

\section{Conclusion}

The $\mathrm{TCl}$ is a new index representing the relationship between the smaller trochlear and larger capitellar angles of the measured elbow. The mean normal index was 0.45 , with a range of $0.25-0.8$, in normal elbows. The $\mathrm{TCl}$ is less dependent on direct measurement of angels than other predictors of elbow alignment. The authors suggest that provided the $\mathrm{TCl}$ is within the normal range there is no need for comparison with the contra lateral elbow. It appears that the TCI might serve as another and possibly more definitive predictor of physics alignment in supracondylar fractures of the elbow and assist accurate reduction achievement. Limitations of the current study include its design being not randomized and retrospective. A further prospective randomized clinical trial should be done prior to making a clear-cut recommendation that $\mathrm{TCl}$ are superior to Baumann's angle measurement for assessment of the accurate reduction of supracondylar fracture in children.

\section{Competing interests}

The authors declare that they have no competing interests.

Authors' contributions

\begin{tabular}{|l|c|c|c|c|c|}
\hline Authors' contributions & LG & RG & ARG & AS & ER \\
\hline Research concept and design & $\checkmark$ & -- & -- & -- & -- \\
\hline Collection and/or assembly of data & -- & $\checkmark$ & -- & -- & -- \\
\hline Data analysis and interpretation & $\checkmark$ & $\checkmark$ & -- & -- & -- \\
\hline Writing the article & $\checkmark$ & -- & $\checkmark$ & -- & -- \\
\hline Critical revision of the article & -- & -- & $\checkmark$ & $\checkmark$ & $\checkmark$ \\
\hline Final approval of article & $\checkmark$ & -- & $\checkmark$ & -- & $\checkmark$ \\
\hline Statistical analysis & -- & $\checkmark$ & -- & $\checkmark$ & -- \\
\hline
\end{tabular}

Publication history

Editors: Ahmet Aslan, Afyonkarahisar State Hospital, Turkey. Steven A. Stuchin, NYU Hospital for Joint Diseases, USA. Senior Editor: Gianpaolo Papaccio, Second University of Naples, Italy.

EIC: Bruce M. Rothschild, Northeast Ohio Medical University, USA. Received: 27-Aug-2014 Final Revised: 02-Apr-2015

Accepted: 16-Apr-2015 Published: 24-Apr-2015

\section{References}

1. Chess DG, Leahey JL and Hyndman JC. Cubitus varus: significant factors. J Pediatr Orthop. 1994; 14:190-2. | Article | PubMed

2. Wilkins KE. Supracondylar fractures: what's new? J Pediatr Orthop B. 1997; 6:110-6. | PubMed

3. Voss FR, Kasser JR, Trepman E, Simmons E, Jr. and Hall JE. Uniplanar supracondylar humeral osteotomy with preset Kirschner wires for posttraumatic cubitus varus. J Pediatr Orthop. 1994; 14:471-8. | Article I PubMed

4. Otsuka NY and Kasser JR. Supracondylar Fractures of the Humerus in Children. J Am Acad Orthop Surg. 1997; 5:19-26. | Article | PubMed

5. Dodge HS. Displaced supracondylar fractures of the humerus in children--treatment by Dunlop's traction. J Bone Joint Surg Am. 1972; 54:1408-18. | Article | PubMed

6. Gorelick L, Robinson D, Loberant N, Rozano-Gorelick A, Yassin M, Garti $A$ and Ram A. Assessment of the normal and pathological alignment of the elbow in children using the trochleocapitellar index. $B M C$ Musculoskelet Disord. 2014; 15:60. I Pdf

7. Worlock P. Supracondylar fractures of the humerus. Assessment of cubitus varus by the Baumann angle. J Bone Joint Surg Br. 1986; 68:7557. | Article | PubMed

8. Wilkins KE. Fractures and dislocations of the elbow region. In Fractures in Children. $2^{\text {nd }}$ edition. Edited by Rockwood CA, Wilkins KE, King RE. Philadelphia: LB Lippincott. 1984; 363-575.

9. Silva M, Pandarinath R, Farng E, Park S, Caneda C, Fong YJ and Penman A. Inter- and intra-observer reliability of the Baumann angle of the humerus in children with supracondylar humeral fractures. Int Orthop. 2010; 34:553-7. | Article | PubMed Abstract | PubMed Full Text

10. Keenan WN and Clegg J. Variation of Baumann's angle with age, sex, and side: implications for its use in radiological monitoring of supracondylar fracture of the humerus in children. J Pediatr Orthop. 1996; 16:97-8. | Article | PubMed

11. Camp J, Ishizue K, Gomez M, Gelberman R and Akeson W. Alteration of Baumann's angle by humeral position: implications for treatment of supracondylar humerus fractures. J Pediatr Orthop. 1993; 13:521-5. | PubMed

12. Pace JL, Wiater B, Schmale G, Jinguji T, Bompadre V and Krengel W, $3 \mathrm{rd}$. Baumann angle and radial-ulnar overlap: a radiographic study to control for the angle of the x-ray beam. J Pediatr Orthop. 2012; 32:46772. | Article | PubMed

13. Pretell-MazziniJ, J Rodriguez-MartinJ, Auñon-Martinl and 
Gorelick et al. Journal of Rheumatology and Orthopedics 2015,

Zafra-JimenezJA. Controversial topics in the management of displacedsupracondylar humerus fractures in children. Strategies Trauma Limb Reconstr. 2011; 6: 43-50. | Article

14. Smajic N, Smajic J, Sadic S, Jasarevic M, Ahmetovic-Djug J and Hodzic R. Correlation between Bauman's and carrying angle in children with supracondylar fracture of humerus. Med Arch. 2013; 67:195-7. | Article I PubMed

15. Dai L. Radiographic evaluation of Baumann angle in Chinese children and its clinical relevance. J Pediatr Orthop B. 1999; 8:197-9. | Article | PubMed

16. Penafort R, Saw A and Sengupta S. Comparison of two methods of percutaneous pin fixation in displaced supracondylar fractures of the humerus in children. J Orthop Surg (Hong Kong). 2004; 12:76-82. | Pdf | PubMed

17. Aslan A, Konya MN, Ozdemir A, Yorgancigil H, Maralcan G and Uysal E. Open reduction and pinning for the treatment of Gartland extension type III supracondylar humeral fractures in children. Strategies Trauma Limb Reconstr. 2014; 9:79-88. | Article | PubMed Abstract | PubMed Full $\underline{\text { Text }}$

\section{Citation:}

Gorelick L, Gelman R, Rozano-Gorelick A, Saab A and Ram E. Preliminary view on new roentgenologic trochleocapitellar index for assessment accuracy of the reduction supracondylar fracture of the elbow in children to comparison Baumann's angle. J Rheumatol Orthop. 2015; 2:1. http://dx.doi.org/10.7243/2055-7000-2-1 